\title{
Differential Evolution-Based PID Control of Nonlinear Full-Car Electrohydraulic Suspensions
}

\author{
Jimoh O. Pedro, ${ }^{1}$ Muhammed Dangor, ${ }^{1}$ Olurotimi A. Dahunsi, ${ }^{1}$ and M. Montaz Alii,3 \\ ${ }^{1}$ School of Mechanical, Industrial and Aeronautical Engineering, University of the Witwatersrand, 1 Jan Smuts Avenue, \\ Private Bag 03, WITS 2050, Johannesburg, South Africa \\ ${ }^{2}$ School of Computation and Applied Mathematics, University of the Witwatersrand, 1 Jan Smuts Avenue, Private Bag 03, \\ WITS 2050, Johannesburg, South Africa \\ ${ }^{3}$ TCSE, Faculty of Engineering and Built Environment, University of the Witwatersrand, 1 Jan Smuts Avenue, Private Bag 03, \\ WITS 2050, Johannesburg, South Africa
}

Correspondence should be addressed to M. Montaz Ali; montaz.ali@wits.ac.za

Received 13 May 2013; Accepted 17 July 2013

Academic Editor: C. M. Khalique

Copyright (C) 2013 Jimoh O. Pedro et al. This is an open access article distributed under the Creative Commons Attribution License, which permits unrestricted use, distribution, and reproduction in any medium, provided the original work is properly cited.

\begin{abstract}
This paper presents a differential-evolution- (DE-) optimized, independent multiloop proportional-integral-derivative (PID) controller design for full-car nonlinear, electrohydraulic suspension systems. The multiloop PID control stabilises the actuator via force feedback and also improves the system performance. Controller gains are computed using manual tuning and through DE optimization to minimise a performance index, which addresses suspension travel, road holding, vehicle handling, ride comfort, and power consumption constraints. Simulation results showed superior performance of the DE-optimized PID-controlled active vehicle suspension system (AVSS) over the manually tuned PID-controlled AVSS and the passive vehicle suspension system (PVSS).
\end{abstract}

\section{Introduction}

The evolution of modern instrumentation and control techniques has made semi-active vehicle suspension systems (SAVSS) [1] and AVSS designs more promising. However, the biggest challenge remains the attainment of trade-offs between the conflicting performance criteria like suspension travel, ride comfort, road holding, and vehicle handling.

Although there is a vast amount of literature documented about AVSS design, most are affected by at least one of the following limitations: use of linear suspension models, ignoring actuator dynamics and performance evaluation based on the 2 degree-of-freedom (dof) quarter-car model $[2,3]$. This work presents a 7 dof full-car nonlinear suspension system that accounts for system complexities associated with inherent nonlinearities, actuator dynamics, and coupling interactions [4].

Linear optimal control schemes like linear quadratic regulator $(\mathrm{LQR})$, linear quadratic gaussian (LQG), $\mathscr{H}_{\infty}$, mixed $\mathscr{H}_{2} / \mathscr{H}_{\infty}$, and linear parameter varying (LPV) control methods are well-developed control schemes that have been employed in SAVSS and AVSS designs [1,4-8]. Their stability and robustness properties are more readily established but always limited when employed for complex nonlinear control schemes; they also normally assume time-invariant situation. Minimising the chosen performance objectives when using these control methods requires that some optimal feedback gains be obtained. Need for measurement of all state variables is another additional challenge. Moreover, solving AVSS control problem by the use of linear control schemes is usually based on the assumption of a broad bandwidth actuator, whose response is fast enough and its parameters can be linearised (the Jacobian way) within some operating regions [9].

Application of nonlinear control methods like feedback linearization (FBL) [4], backstepping, and sliding mode control [10] methods is also well documented among the AVSS control design literature. These methods are able to overcome most of the challenges encountered in the implementation of the linear control methods, but challenges like difficulty 
in establishing system stability and repeated differentiation of nonlinear functions in backstepping lead to additional system complications, and exact FBL is not always possible because full knowledge about the system is unavailable. Moreover, FBL and sliding mode are usually susceptible to chattering that degrades system performance. Availability of good system dynamic model is usually necessary and performance is also readily affected by measurement noise $[4,10-12]$.

Intelligent controllers provide new alternatives with better prospects but they inherit the setbacks of the nonlinear controllers since they are implemented in most cases in combination with the nonlinear control techniques [12-15].

PID control is well known for its simplicity and ease with which its gains can be adjusted. It is also known to have setbacks in its lack of robustness to parameter variations and physical implementation limitations due to high-loop gains [2]. Evidence in the literature shows that tuning of the majority of the industrial PID controllers was either done manually or based on its default setting [16].

Previous works have demonstrated the prospect for superior AVSS performance when PID control is combined with appropriate computational intelligence or global optimization methods, especially for the selection of PID optimal gains. Ziegler Nichols tuning method has been successfully employed over the years in tuning PID controllers but it often requires further fine tuning which has been done manually or intuitively $[9,13,15,17]$.

Evolutionary-based optimization techniques such as genetic algorithms (GA) and particle swarm optimization (PSO) have been successfully applied for controller tuning of linear PID control of quarter-car AVSS [18-20]. Similarly, optimizations of $\mathscr{H}_{\infty}$ and LQR-based control methods were performed with success $[21,22]$. Optimization has also been combined with intelligent control methods to obtain superior performance in some cases [23-25]. With the aid of these evolutionary-based optimization algorithms, the AVSS was able to meet hard design specifications that could not be achieved by conventional tuning methods. The drawback of the proposed methods was the weakness of the cost functions as they were only based on improving ride comfort or vertical body displacement. There was no attempt made to resolve the other conflicting design requirements of an AVSS.

Differential evolution is a heuristic, population set-based direct search global optimization algorithm with numerous applications $[13,17,26-28]$. The global optimization algorithm is inherently flexible and relatively simpler in comparison with other techniques. It gives better search space exploration characteristics with similar or even better results than previously employed optimization routines [26, $29,30]$. Secondly, it applies predefined conditions where new generations are only accepted if they produce enriched and better solutions. Those characteristics slow the routine down but helps to prevent early convergence [31].

Four independent multi-loop PID controllers have been employed in this work to simultaneously control the fullcar AVSS and to ensure actuator stability. Multiobjective DE direct search global optimization algorithm was employed in tuning the multi-loop PID controllers' gains. The objective function simultaneously addressed the conflicting trade-off challenge in the AVSS design.

\section{System Overview and Modelling}

AVSS responds dynamically to road disturbance inputs by inducing relative motion between the body and the wheel through the force generated by the servo-hydraulic actuator. Obtaining the appropriate control voltage for the actuator requires an optimal trade-off between the design objectives in the presence of road disturbance inputs. The success of this process yields a suspension system that is adaptive to the road disturbance and other operating conditions.

Figure 1 presents the generic AVSS feedback control loop. The system consists of a controller issuing the command input signal to the actuator to generate a manipulating signal. Better command input signal is sent because the controller output is optimized by the use of evolutionary algorithms.

2.1. Physical Modelling. Figure 2 shows the seven dof fullcar suspension system used in this study. $M_{s}, I_{\theta}$, and $I_{\phi}$ are the sprung mass, pitch inertia, and roll inertia of the vehicle, respectively; $l_{f}, l_{r}$, and $t_{f}$ are the distance from the vehicle front axle to the centre of gravity, the distance from the vehicle rear axle to the centre of gravity, and the half width of the vehicle, respectively. $z, \theta$, and $\phi$ are the vehicle body heave, pitch, and roll, respectively; the displacement and mass of each wheel are denoted as $z_{t_{i j}}$ and $m_{u_{i j}}$ respectively with $(i, j)$ representing the position of the tyre, where $i$ refers to the lateral position front $f$ or rear $r$, and $j$ to the longitudinal position right $r$ or left $l$, and the respective road disturbance profile at each wheel is given as $w_{i j}$. The spring and damping force contributions of the suspension system are denoted by $F_{k_{i j}}$ and $F_{b_{i j}}$, respectively, and those of the tyre are denoted by $F_{k t_{i j}}$ and $F_{b t_{i j}}$, respectively. $F_{a_{i j}}$ is the actuator force supplied between the chassis and each wheel. The suspension travels are denoted by $z_{i j}[4]$.

2.2. Mathematical Modelling. The governing equations are derived using Newton-Euler approach, with the resultant force acting in each suspension system given as

$$
F_{i j}=F_{k_{i j}}+F_{b_{i j}}-F_{a_{i j}}
$$

The heave, pitch, and roll dynamics of the vehicle are [4]

$$
\begin{gathered}
M_{s} \ddot{z}=F_{f r}+F_{f l}+F_{r r}+F_{r l}, \\
I_{\theta} \ddot{\theta}=-F_{f r} l_{f}-F_{f l} l_{f}+F_{r r} l_{r}+F_{r l} l_{r}, \\
I_{\phi} \ddot{\phi}=t_{f}\left[F_{f r}-F_{f l}+F_{r r}-F_{r l}\right] .
\end{gathered}
$$

The dynamics of each wheel are determined as follows:

$$
m_{u_{i j}} \ddot{z}_{t_{i j}}=-F_{k_{i j}}-F_{b_{i j}}+F_{a_{i j}}+F_{k t_{i j}}+F_{b t_{i j}} .
$$




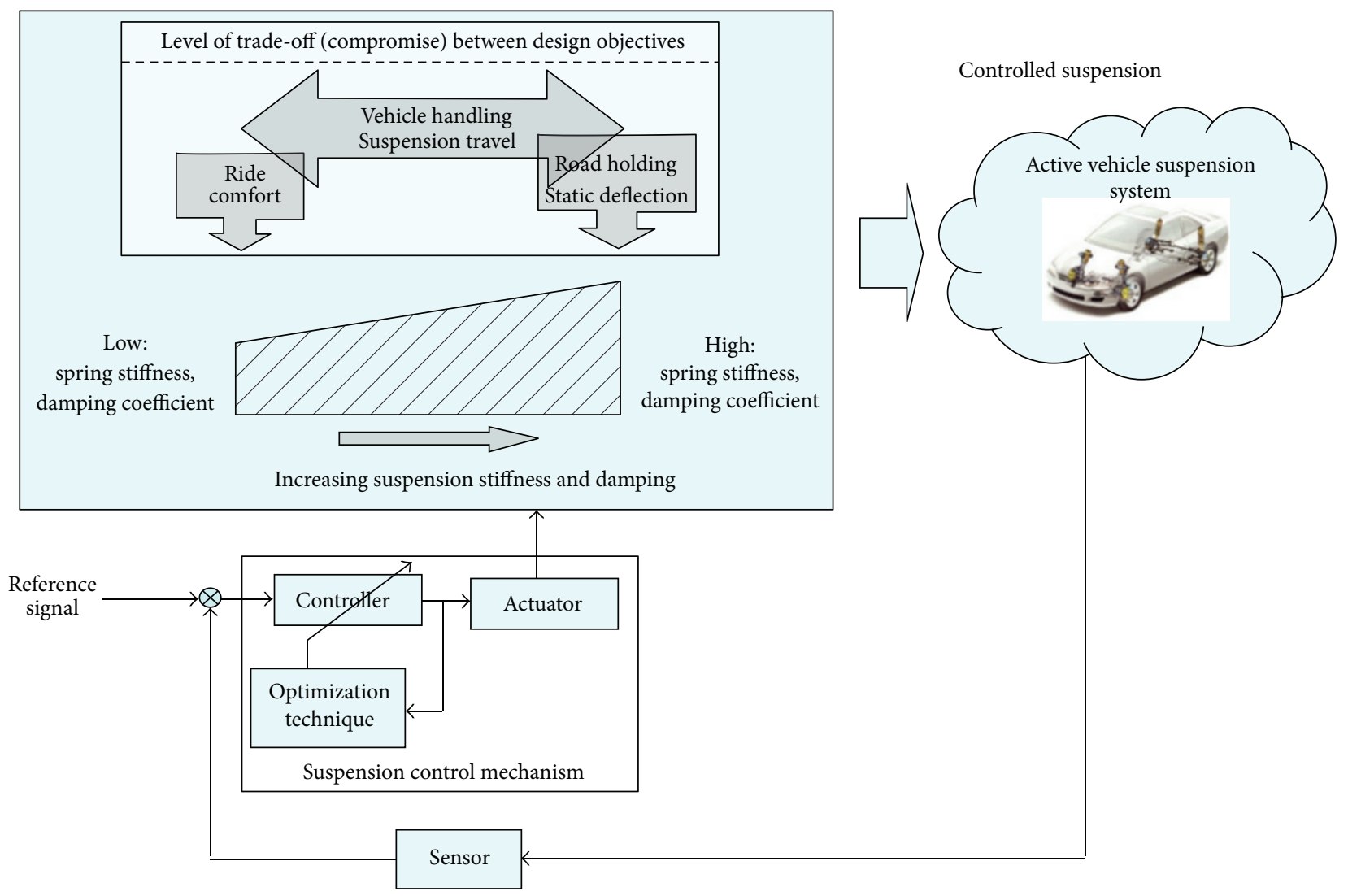

FIGURE 1: AVSS feedback control loop.

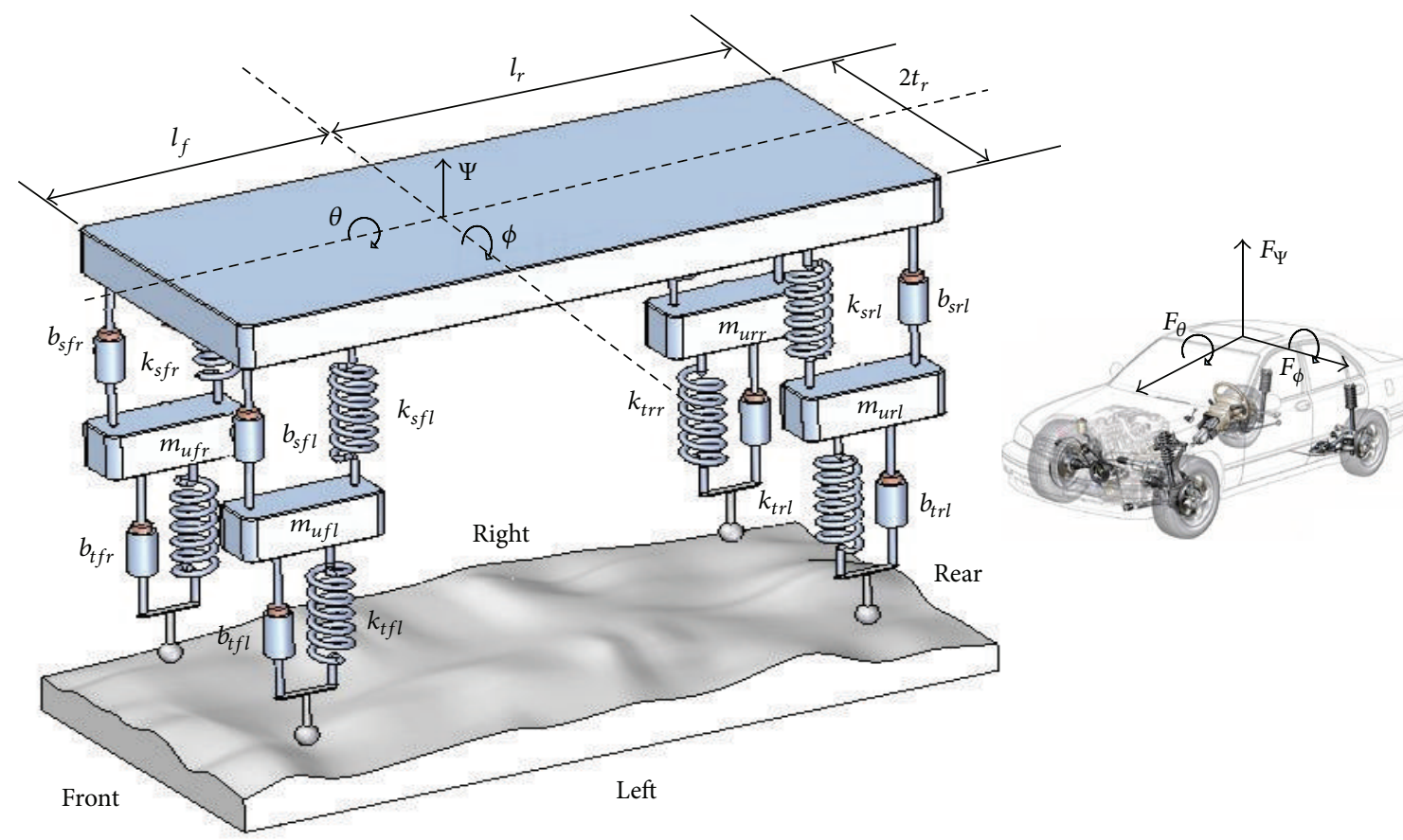

FIGURE 2: Simplified full-car model of the active vehicle suspension system. 
The suspension travel at each wheel is determined as

$$
\begin{aligned}
& z_{f l}=z-l_{f} \sin \theta-t_{f} \sin \phi, \\
& z_{r l}=z+l_{r} \sin \theta-t_{f} \sin \phi, \\
& z_{f r}=z-l_{f} \sin \theta+t_{f} \sin \phi, \\
& z_{r r}=z+l_{f} \sin \theta+t_{f} \sin \phi .
\end{aligned}
$$

The suspension spring and damping forces are computed as

$$
\begin{aligned}
F_{k_{i j}}= & k_{s_{i j}}^{l}\left(z_{t_{i j}}-z_{i j}\right)+k_{s_{i j}}^{\mathrm{nl}}\left(z_{t_{i j}}-z_{i j}\right)^{3}, \\
F_{b_{i j}}= & b_{s_{i j}}^{l}\left(\dot{z}_{t_{i j}}-\dot{z}_{i j}\right) \\
& +b_{s_{i j}}^{\mathrm{nl}} \sqrt{\left|\dot{z}_{t_{i j}}-\dot{z}_{i j}\right|} \operatorname{sgn}\left(\dot{z}_{t_{i j}}-\dot{z}_{i j}\right) \\
= & b_{s_{i j}}^{\mathrm{sym}}\left|\dot{z}_{t_{i j}}-\dot{z}_{i j}\right|
\end{aligned}
$$

with linear and nonlinear suspension spring coefficients $k_{s_{i j}}^{l}$ and $k_{s_{i j}}^{\mathrm{nl}}$, and linear, nonlinear, and symmetric damping coefficients $b_{s_{i j}}^{l}, b_{s_{i j}}^{\mathrm{nl}}$, and $b_{s_{i j}}^{\mathrm{sym}}$, respectively. The dynamics of the tyres are modelled as

$$
\begin{aligned}
& F_{k t_{i j}}=k_{t_{i j}}\left(w_{i j}-z_{t_{i j}}\right), \\
& F_{b t_{i j}}=b_{t_{i j}}\left(w_{i j}-z_{t_{i j}}\right),
\end{aligned}
$$

where $k_{t_{i j}}$ and $b_{t_{i j}}$ are the spring and damping coefficients of the wheel. The pressure developed by the servo-hydraulic actuators is modelled as $[4,32]$

$$
\dot{P}_{L_{i j}}=\gamma_{i j} \Phi_{i j} x_{v_{i j}}-\beta_{i j} P_{L_{i j}}+\alpha_{i j} A_{i j} \dot{z}_{i j}
$$

where

$$
\begin{aligned}
\alpha_{i j} & =\frac{4 \beta_{e_{i j}}}{V_{t_{i j}}}, \quad \beta_{i j}=\alpha_{i j} C_{t p_{i j}}, \\
\gamma_{i j} & =C_{d_{i j}} S_{i j} \sqrt{\frac{1}{\rho_{i j}}}, \quad \Phi_{i j}=\phi_{1_{i j}} \times \phi_{2_{i j}}, \\
\phi_{1_{i j}} & =\operatorname{sgn}\left(P_{s_{i j}}-\operatorname{sgn}\left(x_{v_{i j}}\right) P_{L_{i j}}\right), \\
\phi_{2_{i j}} & =\sqrt{\left|P_{s_{i j}}-\operatorname{sgn}\left(x_{v_{i j}}\right) P_{L_{i j} \mid}\right|}
\end{aligned}
$$

where $x_{v_{i j}}$ are the spool-valves' displacements, $P_{s_{i j}}$ are the supply pressures, $A_{i j}$ are the pistons' cross-sectional areas, $V_{t_{i j}}$ are the volumes of the cylinders, $\beta_{e_{i j}}$ are the bulk moduli of the working fluids, $\Phi_{i j}$ are the hydraulic load flows, $C_{t p_{i j}}$ are the leakage coefficients.

$C_{d_{i j}}$ are the discharge coefficients between the supply lines and the hydraulic cylinders and $S_{i j}$ are spool-valves' area gradients. The valves' positions are modelled with first-order lag as follows:

$$
\dot{x}_{v_{i j}}=\frac{1}{\tau_{i j}}\left(K_{v_{i j}} u_{i}-x_{v_{i j}}\right) \text {, }
$$

where $K_{v_{i j}}$ are the servo-valves' gains and $\tau_{i j}$ are the time constants. The disturbance is a deterministic road bump. The vehicle approaches a sinusoidal bump at $40 \mathrm{~km} / \mathrm{h}$. The heights of the bump on the right and left sides are 4 and $6 \mathrm{~cm}$, respectively, such that roll motion is induced. The road profile at each wheel is given as

$$
\begin{gathered}
w_{f r}= \begin{cases}a_{1} \frac{(1-\cos 2 \pi(V / \lambda) t)}{2} & 0.45 \leq t \leq 0.9 \\
0 & \text { otherwise, }\end{cases} \\
w_{f l}= \begin{cases}a_{2} \frac{(1-\cos 2 \pi(V / \lambda) t)}{2} & 0.45 \leq t \leq 0.9 \\
0 & \text { otherwise, }\end{cases} \\
w_{r r}=w_{r l} \\
= \begin{cases}a_{1} \frac{(1-\cos 2 \pi(V / \lambda) t)}{2} & 0.45+\frac{\lambda}{V} \leq t \leq 0.9+\frac{\lambda}{V} \\
0 & \text { otherwise, }\end{cases}
\end{gathered}
$$

where $a_{1}$ and $a_{2}$ are the amplitudes of the bump, $V$ is the horizontal speed, and $\lambda$ is the wavelength of the bump. Values of the system parameters are given in Table 1.

\section{System Performance Specification and Evaluation}

3.1. Performance Specifications. The following characteristics are required of the AVSS controller in a bid to meet the set performance objectives.

(1) Nominal stability: the closed loops should be nominally stable. Stability in the inner loop is enhanced through a force feedback loop. The enhanced stability of the actuator dynamics should improve the overall system stability.

(2) Disturbance rejection: the controller should demonstrate good low frequency disturbance attenuation.

(3) Good command following: the suspension travel response of the AVSS is examined in the presence of the deterministic road inputs shown. The controller should be able to keep the steady-state error as close to zero as possible.

(4) Suspension travel is constrained to physical limits to avoid damages due to topping and bottoming. Thus it is not to exceed $\pm 0.1 \mathrm{~m}$ [33]. 
TABle 1: Parameters of the full-car model.

\begin{tabular}{|c|c|}
\hline Parameters & Value \\
\hline Sprung mass $\left(M_{s}\right)$ & $1060 \mathrm{~kg}$ \\
\hline Unsprung masses $\left(m_{u_{i j}}\right)$ & $40,40,35,35 \mathrm{~kg}$ \\
\hline Pitch moment of inertia $\left(I_{\theta}\right)$ & $2200 \mathrm{kgm}^{2}$ \\
\hline Roll moment of inertia $\left(I_{\phi}\right)$ & $460 \mathrm{kgm}^{2}$ \\
\hline Distance from vehicle front axle to its centre of gravity $\left(l_{f}\right)$ & $1 \mathrm{~m}$ \\
\hline Distance from vehicle rear axle to its centre of gravity $\left(l_{r}\right)$ & $1.5 \mathrm{~m}$ \\
\hline Vehicle width $\left(t_{f}\right)$ & $1.5 \mathrm{~m}$ \\
\hline Linear suspension stiffness at each wheel $\left(k_{s_{i j}}^{l}\right)$ & $2.35 \times 10^{4} \mathrm{~N} / \mathrm{m}$ \\
\hline Nonlinear suspension stiffness at each wheel $\left(k_{s_{i j}}^{\mathrm{nl}}\right)$ & $2.35 \times 10^{6} \mathrm{~N} / \mathrm{m}$ \\
\hline Tyre stiffness at each wheel $\left(k_{t_{i j}}\right)$ & $1.9 \times 10^{5} \mathrm{~N} / \mathrm{m}$ \\
\hline Linear suspension damping at each wheel $\left(b_{s_{i j}}^{l}\right)$ & $700 \mathrm{Ns} / \mathrm{m}$ \\
\hline Nonlinear suspension damping at each wheel $\left(b_{s_{i j}}^{\mathrm{nl}}\right)$ & $400 \mathrm{Ns} / \mathrm{m}$ \\
\hline Asymmetric suspension damping at each wheel $\left(b_{s_{i j}}^{\text {sym }}\right)$ & $400 \mathrm{Ns} / \mathrm{m}$ \\
\hline Tyre damping at each wheel $\left(b_{t_{i j}}\right)$ & $80,70 \mathrm{Ns} / \mathrm{m}$ \\
\hline Actuator parameter $\left(\alpha_{i j}\right)$ & $4.515 \times 10^{13}$ \\
\hline Actuator parameter $\left(\beta_{i j}\right)$ & 1 \\
\hline Actuator parameter $\left(\gamma_{i j}\right)$ & $1.545 \times 10^{9}$ \\
\hline Piston area $\left(A_{i j}\right)$ & $3.35 \times 10^{-4} \mathrm{~m}^{2}$ \\
\hline Supply pressure $\left(P_{s_{i j}}\right)$ & $10,342,500 \mathrm{~Pa}$ \\
\hline Time constant $\left(\tau_{i j}\right)$ & $3.33 \times 10^{-2} \mathrm{~s}$ \\
\hline Servo-valve gains $\left(K_{v_{i j}}\right)$ & $0.001 \mathrm{~m} / \mathrm{V}$ \\
\hline Bump amplitudes $\left(a_{1}, a_{2}\right)$ & $4,6 \mathrm{~cm}$ \\
\hline Bump wavelength $(\lambda)$ & $5 \mathrm{~m}$ \\
\hline Vehicle speed $(V)$ & $40 \mathrm{~km} / \mathrm{h}$ \\
\hline
\end{tabular}

(5) The control voltage is also limited to $\pm 10 \mathrm{~V}$.

(6) The maximum actuator force must be less than the static weight of the vehicle; that is, $F_{\text {hyd }}<m_{s} g$.

(7) For good road holding, the dynamic load that is transmitted through the road should not be larger than the static weight of the vehicle.

(8) Ride comfort: this is quantified using the vehicle body acceleration in the vertical direction. The vertical acceleration of the vehicle body needs to be minimal for a good ride comfort, especially within the low frequency band of 0.1 to $10 \mathrm{~Hz}$. The peak sprung mass acceleration is $\ddot{z}<4.5 \mathrm{~m} / \mathrm{s}^{2}$ [34-38].

3.2. Optimal Trade-Off among Performance Criteria. The objective function employed in the optimisation algorithms is presented in (11). It is designed to minimise the suspension travels, $y_{i}$, actuators' forces, $F_{a_{i j}}$, sprung mass acceleration, $\ddot{z}$, control voltages, $u_{i}$, and wheels' dynamic loads. This way, ride comfort and road holding are improved while control voltages and actuator forces are kept as small as possible.

The objective of the proposed controller is to minimise the performance index:

$$
\begin{aligned}
& J=J_{1}+J_{2}+J_{3}+J_{4}+J_{5}, \\
& J_{1}=\frac{1}{T} \int_{0}^{T}\left[\left(\frac{\ddot{z}}{\ddot{z}_{\max }}\right)^{2}+\left(\frac{\ddot{\theta}}{\ddot{\theta}_{\max }}\right)^{2}+\left(\frac{\ddot{\phi}}{\ddot{\phi}_{\max }}\right)^{2}\right] d t, \\
& J_{2}=\sum_{j=f r} \sum_{i=r l} \frac{1}{T} \int_{0}^{T}\left[\left(\frac{F_{k t_{i j}}+F_{b t_{i j}}}{\left(F_{k t_{i j}}+F_{b t_{i j}}\right)_{\max }}\right)^{2}\right] d t, \\
& J_{3}=\sum_{i=1}^{4} \frac{1}{T} \int_{0}^{T}\left[\left(\frac{y_{i}}{y_{i_{\max }}}\right)^{2}\right] d t, \\
& J_{4}=\sum_{j=f r} \sum_{i=r l} \frac{1}{T} \int_{0}^{T}\left(\frac{F_{a_{i j}}}{F_{a_{i j} \max }}\right)^{2} d t, \\
& J_{5}=\sum_{i=1}^{4} \frac{1}{T} \int_{0}^{T}\left[\left(\frac{u_{i}}{u_{i_{\max }}}\right)^{2}\right] d t,
\end{aligned}
$$

where $J$ is the performance index, $J_{1}, J_{2}, J_{3}, J_{4}$, and $J_{5}$ relate to the vehicle ride comfort and vehicle handling, road holding properties, suspension travel, actuation force, and power consumption, respectively, $\ddot{z}_{\max }, \ddot{\theta}_{\max }, \ddot{\phi}_{\max },\left(F_{k t_{i j}}+F_{b t_{i j}}\right)_{\max }$, $y_{i_{\max }}, F_{a_{i j_{\max }}}$, and $u_{i_{\max }}$ are the maximum allowable heave body acceleration, pitch acceleration, roll acceleration, tyre 


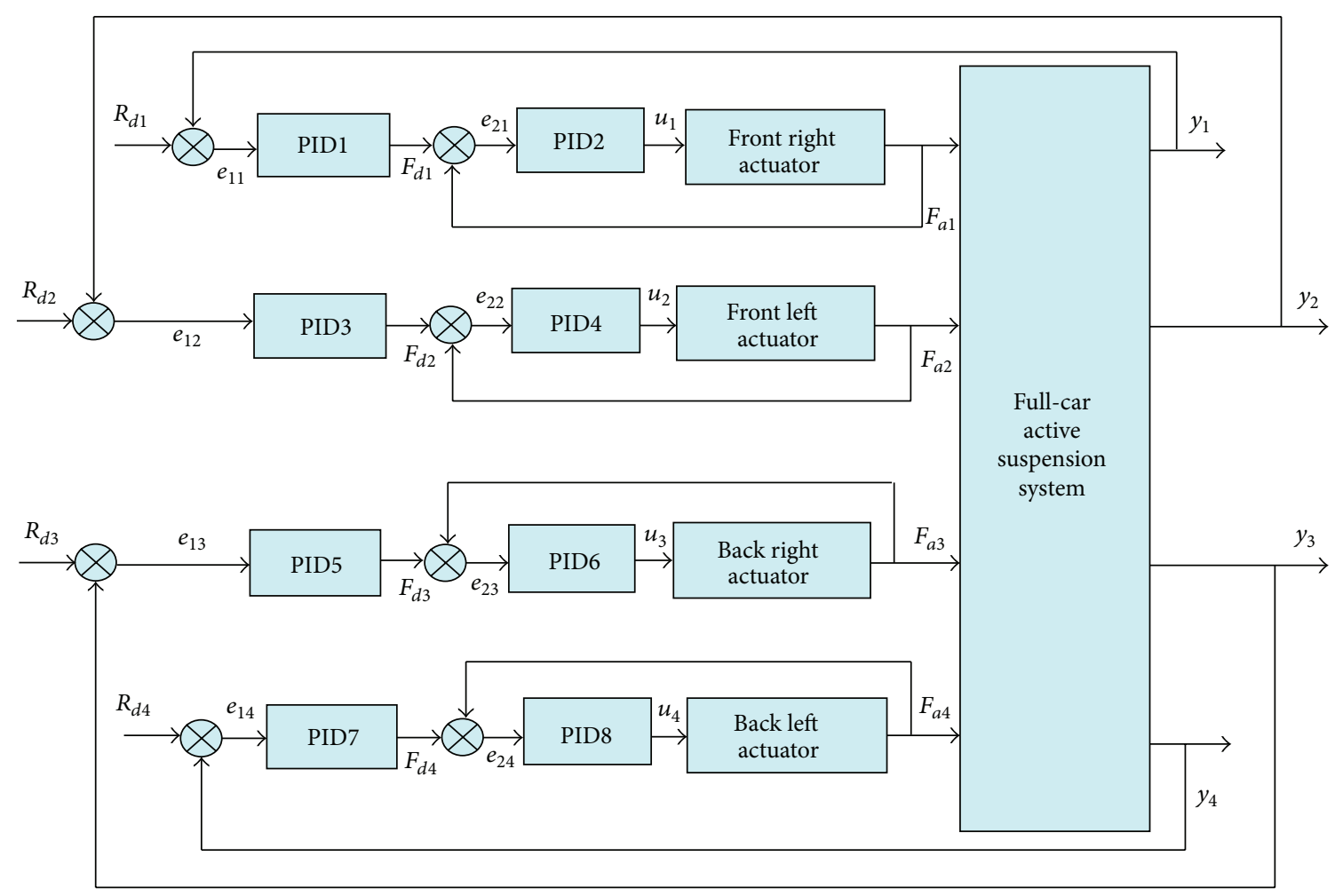

FIGURE 3: Control architecture of the proposed multiloop PID controller.

dynamic load, suspension travels, actuation forces, and control input voltages, respectively, $T$ is the period over which the simulation runs. The controller gains are determined either using manual tuning or through DE.

\section{Controller Design}

The control system is made up of multiple control loops: four outer control loops are used to regulate the controlled variables, while the four inner control loops are used to stabilise the hydraulic actuators [2]. Figure 3 shows the proposed control architecture. The controlled variables are the suspension travel at each of the wheels and force developed by the actuator is fed back in the inner control loops.

PID controllers are described as follows:

$$
u_{i j}=K_{P_{i j}} e_{i j}(t)+K_{D_{i j}} \frac{d e_{i j}(t)}{d t}+K_{I_{i j}} \int_{0}^{T} e_{i j}(t) d t,
$$

where $K_{P_{i j}}$ are the proportional gains, $K_{D_{i j}}$ are the derivative gains, $K_{I_{i j}}$ are the integral gains, and the error signals $e_{i j}$ are given as

$$
\begin{aligned}
e_{i j} & =y_{d_{i j}}(t)-y_{i j}(t) \\
& =R_{d}(t)-y_{i j}(t),
\end{aligned}
$$

where $y_{d_{i j}}(t)$ are the desired suspension travels. Thus this investigation addresses the issue of regulation, and the desired setpoints are hence set to zero.
4.1. Differential Evolution Optimization Method. Differential evolution is another heuristic routine and operates by firstly generating a uniformly distributed population $S=$ $\left\{x_{1}, x_{2}, \ldots, x_{N}\right\}$ to search a feasible region, where each vector denotes a set of PID gains. For each iteration, every vector in $S$ is targeted with the objective of being altered such that its fitness improves. This alteration consists of three steps. Firstly, three distinctive individuals apart from the targeted individual, $x_{p(1)}, x_{p(2)}$, and $x_{p(3)}$, are selected randomly and are thereafter utilized to produce a mutant vector using (14) [26]:

$$
\widehat{x}_{i}=x_{p(1)}+F\left(x_{p(2)}-x_{p(3)}\right) \text {, }
$$

where $F>0$ is a scaling factor and $x_{p(1)}$ is known as the base vector. If the point $\widehat{x}_{i} \notin \Omega$, then the mutation operation is repeated. The trial point $y_{i}$ is found from its parents $x_{i}$ and $\widehat{x}_{i}$ using the following crossover rule:

$$
y_{i}^{j}= \begin{cases}\widehat{x}_{i}^{j} & \text { if } R^{j} \leq C_{R} \text { or } j=I_{i} \\ x_{i}^{j} & \text { if } R^{j}>C_{R} \text { and } j \neq I_{i},\end{cases}
$$

where $I_{i}$ denotes a randomly selected integer, which is an element of the set $I=I_{1}, I_{2}, \ldots, I_{n}$, superscript $j$ signifies the $j$ th component of the respective vectors, and $R^{j} \in(0,1)$ is a vector of random numbers drawn for each $j$. The ultimate aim of the crossover rule (15) is to obtain the trial vector $y_{i}$ with components coming from the components of target vector $x_{i}$ and mutated vector $\widehat{x}_{i}$. And this is ensured by introducing $C_{R}$ and the set $I$. Notice that for $C_{R}=1$ the trial vector $y_{i}$ is the 


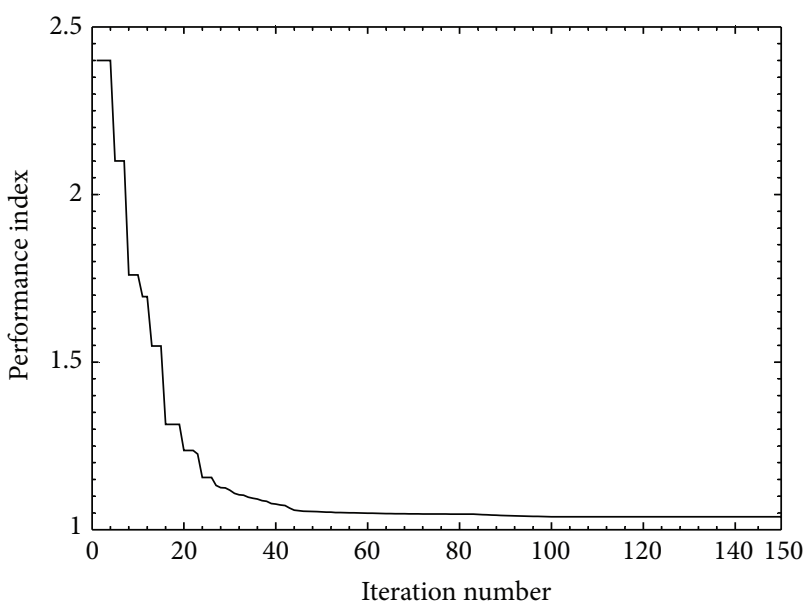

Figure 4: Convergence history of performance index through the use of differential evolution algorithm.

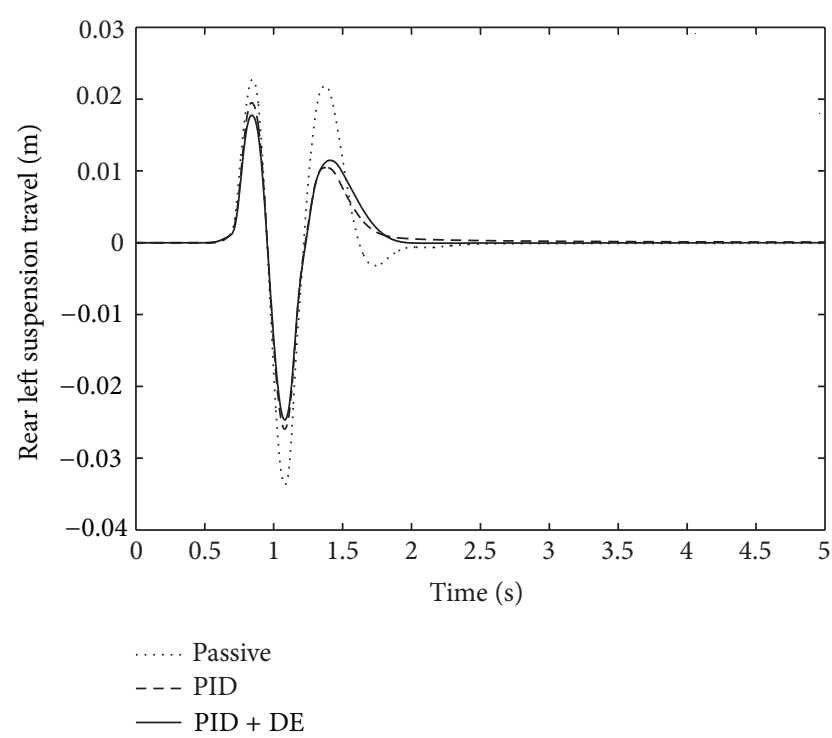

FIGURE 5: Time response of the rear left suspension travel for the passive and the proposed tuning methods.

replica of the mutated vector $\widehat{x}_{i}$. The effect of $C_{R}$ has been studied in $[26,31]$ and it was found that $C_{R}=0.5$ is a good choice. The targeting process continues until all members of $S$ are considered. After all $N$ trial points $y_{i}$ have been generated, acceptance is applied. In the acceptance phase, the function value at the trial point, $f\left(y_{i}\right)$, is compared to $f\left(x_{i}\right)$, the value at the target point. If $f\left(y_{i}\right)<f\left(x_{i}\right)$, then $y_{i}$ replaces $x_{i}$ in $S$; otherwise, $S$ retains the original $x_{i}$. Reproduction (mutation and crossover) and acceptance continue until some stopping conditions are met.

\section{Algorithm: The DE Algorithm}

Step 1. Determine the initial set $S=\left\{x_{1}, x_{2}, \ldots, x_{N}\right\}$, where the points $x_{i}, i=1,2, \ldots, N$, are sampled randomly in $\Omega$;

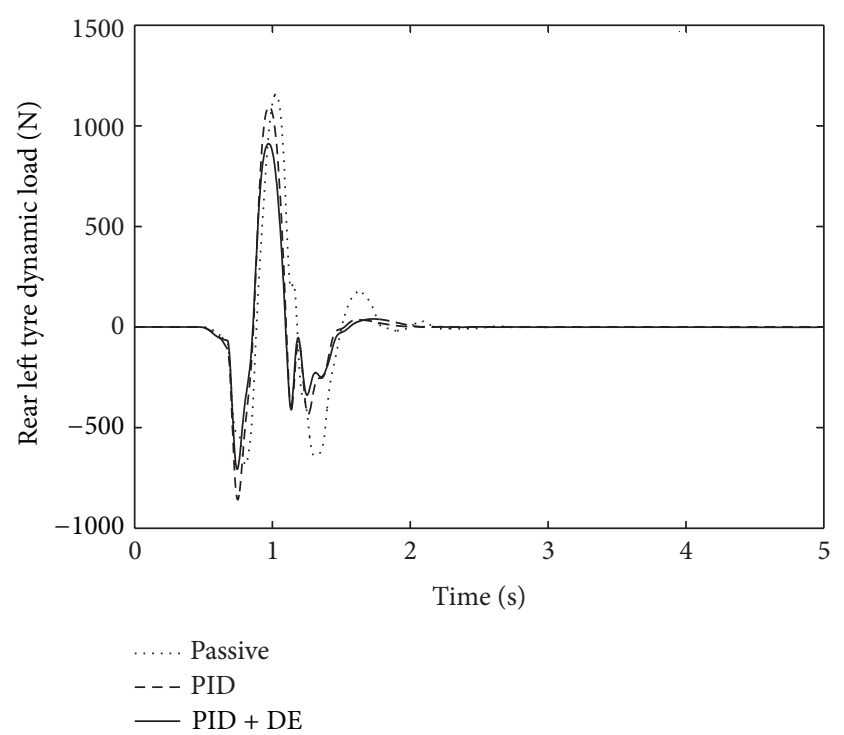

FIgure 6: Time response of the rear left tyre dynamic load for the passive and the proposed tuning methods.

evaluate $f(x)$ at each $x_{i}, i=1,2, \ldots, N$. Set iteration counter $k=0$.

Step 2. Stopping condition: if the stopping condition such as $k>k_{\max }$ is satisfied, then stop.

Step 3. Generate points to replace points in $S$ for the next population (or iteration). For each $x_{i} \in S(i=1,2, \ldots, N)$, determine $y_{i}$ by the following two operations.

(i) Mutation: $\widehat{x}_{i}=x_{p(1)}+F\left(x_{p(2)}-x_{p(3)}\right)$, where $x_{p(1)}$, $x_{p(2)}$, and $x_{p(3)}$ are three random vectors from $S$ and $F$ is a scaling factor, chosen randomly. The tournament selection is applied for each $i$. If the $j$ th component $\widehat{x}_{i}^{j} \notin \Omega$, then it is generated randomly.

(ii) Crossover: calculate the trial vector $y_{i}$ corresponding to the target $x_{i}$ from $x_{i}$ and $\widehat{x}_{i}$ using the crossover rule (15).

Step 4. Acceptance rule to replace points in $S$ : select each trial vector $y_{i}$ for the $k+1$ iteration using the acceptance criterion: replace $x_{i} \in S$ with $y_{i}$ if $f\left(y_{i}\right)<f\left(x_{i}\right)$, otherwise retain, $x_{i}$. Set $k:=k+1$ and go to Step 2 .

We have used $C_{R}=0.5, F=0.75, k_{\max }=500$, and $N=100$. The individual $x_{0}$ of the population $S$ was chosen as an initial condition to be used by the algorithm. It had a performance index of 2.4. The evolution of the performance index from this initial condition is plotted in Figure 4, and the controller gains selected for the manually tuned and DEoptimized cases are listed in Table 2.

\section{Simulation Results and Discussion}

This paper investigates a novel tuning method, which uses DE optimization to compute gains with the objective of 
TABLE 2: PID tuning parameters.

\begin{tabular}{|c|c|c|c|c|c|c|}
\hline \multirow{2}{*}{ Technique } & \multicolumn{3}{|c|}{ Outer PID loop gains } & \multicolumn{3}{|c|}{ Inner PID loop gains } \\
\hline & $K_{p}$ & $K_{i}$ & $K_{d}$ & $k_{p}$ & $k_{i}$ & $k_{d}$ \\
\hline & \multicolumn{6}{|c|}{ Front right suspension system } \\
\hline Manual & 1100 & 360 & 140 & 0.002 & 0.001 & 0 \\
\hline \multirow[t]{2}{*}{$\mathrm{DE}$} & 5837.262 & 239.436 & -123.923 & $4.783 \times 10^{-3}$ & $2.563 \times 10^{-3}$ & $3.618 \times 10^{-9}$ \\
\hline & \multicolumn{6}{|c|}{ Front left suspension system } \\
\hline Manual & 1050 & 170 & 220 & 0.002 & 0.001 & 0 \\
\hline \multirow[t]{2}{*}{$\mathrm{DE}$} & 1692.418 & 267.7925 & 166.1722 & 0.003855 & 0.001056 & $3.124 \times 10^{-9}$ \\
\hline & \multicolumn{6}{|c|}{ Rear right suspension system } \\
\hline Manual & 1200 & 340 & 150 & 0.002 & 0.001 & 0 \\
\hline \multirow[t]{2}{*}{$\mathrm{DE}$} & 5051.295 & 269.968 & 702.321 & 0.003084 & 0.001891 & $3.117 \times 10^{-9}$ \\
\hline & \multicolumn{6}{|c|}{ Rear left suspension system } \\
\hline Manual & 1000 & 200 & 200 & 0.002 & 0.001 & 0 \\
\hline $\mathrm{DE}$ & 3762.704 & -54.3744 & -415.94 & 0.004145 & 0.004006 & $1.992 \times 10^{-9}$ \\
\hline
\end{tabular}

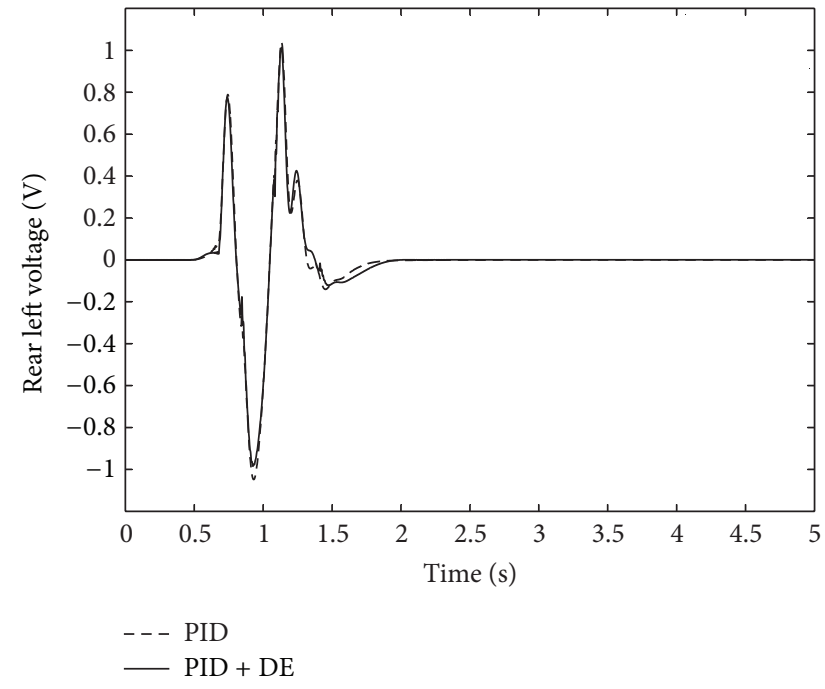

FIGURE 7: Time response of the rear left control input voltage for the proposed tuning methods.

firstly improving the overall performance index of an AVSS and secondly finding the best compromise between these conflicting performance criteria. Simulations were executed in MATLAB/Simulink. Thus far, it was shown in Figure 4 that the DE-optimized case was able to minimize the performance index, but this information alone cannot guarantee that the trade-offs between the various performance criterion have been resolved. Thus, it is still imperative that the AVSS system response in each performance criteria must be analysed to test the effectiveness of DE optimization algorithm in performing its objectives.

The conflicting performance criteria results reported include the suspension travel at each wheel, road holding which is directly related to the force experienced by each of the tyres, ride comfort which is essentially analysed through the body-heave acceleration, vehicle handling which primarily is a function of roll and pitch accelerations, and

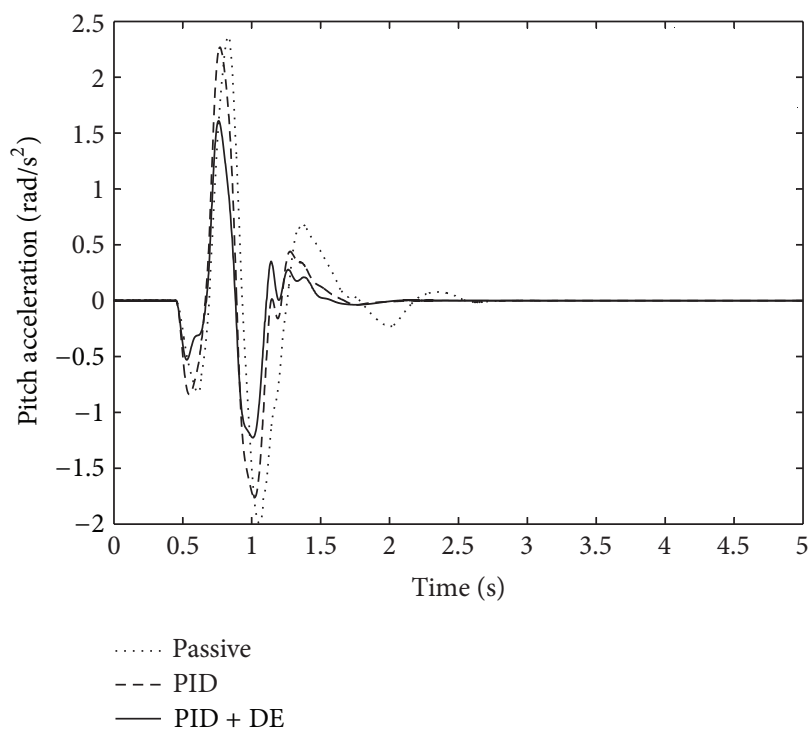

FIGURE 8: Time response of the pitch acceleration for the passive and the proposed tuning methods.

power consumption which is the voltage utilised at each actuator and the resulting hydraulic force, each of which are plotted in Figures 5-11, respectively. The suspension travel, road holding, and power consumption at the rear left wheel were only considered as it possessed the worst response in each of these facets. The root-mean-square (RMS) and peak values of all suspension performance criteria are listed in Table 3.

The suspension travel response shown in Figure 5 indicated a considerable improvement in terms of peak and RMS values when using control. Furthermore, there was an improvement in transient behaviour where the controlled cases had one less oscillation. DE-optimized PID controller tuning produced marginally better peaks and RMS values than the manually tuned case and had a slightly quicker settling time (see Table 3). Such response of the DE-based 
TABLE 3: RMS and peak values of all the suspension performance criteria.

\begin{tabular}{|c|c|c|c|c|}
\hline Technique & RMS & Peak & RMS & Peak \\
\hline & \multicolumn{2}{|c|}{ Front right suspension travel $(\mathrm{m})$} & \multicolumn{2}{|c|}{ Front left suspension travel (m) } \\
\hline Passive & 0.01313 & 0.04816 & 0.01079 & 0.03815 \\
\hline Manual & 0.00915 & 0.03922 & 0.00667 & 0.02942 \\
\hline \multirow[t]{2}{*}{$\mathrm{DE}$} & 0.00943 & 0.03915 & 0.00676 & 0.02516 \\
\hline & \multicolumn{2}{|c|}{ Rear right suspension travel (m) } & \multicolumn{2}{|c|}{ Rear Left suspension travel (m) } \\
\hline Passive & 0.00798 & 0.03398 & 0.00766 & 0.03367 \\
\hline Manual & 0.00866 & 0.03483 & 0.00557 & 0.02593 \\
\hline \multirow[t]{2}{*}{$\mathrm{DE}$} & 0.00678 & 0.02863 & 0.00545 & 0.024698 \\
\hline & \multicolumn{2}{|c|}{ Front right tyre dynamic load $(\mathrm{N})$} & \multicolumn{2}{|c|}{ Front Left tyre dynamic load (N) } \\
\hline Passive & 395.74 & 1594.05 & 321.46 & 1254.53 \\
\hline Manual & 321.18 & 1531.90 & 263.39 & 1295.15 \\
\hline \multirow[t]{2}{*}{$\mathrm{DE}$} & 189.83 & 984.83 & 132.095 & 713.38 \\
\hline & \multicolumn{2}{|c|}{ Rear right tyre dynamic load $(\mathrm{N})$} & \multicolumn{2}{|c|}{ Rear left tyre dynamic load (N) } \\
\hline Passive & 248.95 & 1194.39 & 240.81 & 1158.58 \\
\hline Manual & 248.77 & 1234.10 & 218.73 & 1096.45 \\
\hline \multirow[t]{2}{*}{$\mathrm{DE}$} & 229.63 & 1196.07 & 185.24 & 930.12 \\
\hline & \multicolumn{2}{|c|}{ Front right control input voltage (V) } & \multicolumn{2}{|c|}{ Front left control input voltage (V) } \\
\hline Passive & N/A & N/A & N/A & N/A \\
\hline Manual & 0.3166 & 1.4946 & 0.2256 & 1.0739 \\
\hline \multirow[t]{2}{*}{$\mathrm{DE}$} & 0.3189 & 1.6125 & 0.2255 & 1.1875 \\
\hline & \multicolumn{2}{|c|}{ Rear right control input voltage (V) } & \multicolumn{2}{|c|}{ Rear left control input voltage (V) } \\
\hline Passive & $\mathrm{N} / \mathrm{A}$ & N/A & $\mathrm{N} / \mathrm{A}$ & N/A \\
\hline Manual & 0.2659 & 1.3492 & 0.2129 & 1.0484 \\
\hline \multirow[t]{2}{*}{$\mathrm{DE}$} & 0.2786 & 1.3710 & 0.2044 & 1.0156 \\
\hline & \multicolumn{2}{|c|}{ Pitch acceleration $\left(\mathrm{rad} / \mathrm{s}^{2}\right)$} & \multicolumn{2}{|c|}{ Roll acceleration $\left(\mathrm{rad} / \mathrm{s}^{2}\right)$} \\
\hline Passive & 0.5163 & 2.3672 & 0.1308 & 0.5885 \\
\hline Manual & 0.4631 & 2.2687 & 0.1169 & 0.5388 \\
\hline \multirow{2}{*}{$\mathrm{DE}$} & 0.3140 & 1.6223 & 0.06685 & 0.3289 \\
\hline & \multicolumn{2}{|c|}{ Heave acceleration $\left(\mathrm{m} / \mathrm{s}^{2}\right)$} & \multicolumn{2}{|c|}{ Cumulative actuation force $(\mathrm{N})$} \\
\hline Passive & 0.6488 & 2.4473 & N/A & N/A \\
\hline Manual & 0.4298 & 1.5946 & 498.569 & 1849.75 \\
\hline $\mathrm{DE}$ & 0.3070 & 1.7250 & 342.1241 & 1363.52 \\
\hline
\end{tabular}

PID-controlled case was expected as suspension travel was a major factor in the cost function of the algorithm.

Figures 6, 8, 9, and 10 showed a similar trend in the road holding, pitch, roll, and body-heave accelerations, respectively. This is for the very same reason that these aforementioned responses significantly affected the performance index. Moreover, in these criteria, the variations in peak and RMS values between the DE-optimized and manually tuned PID-controlled cases, as shown in Table 3, were much greater. This was because the weighting factors of these criteria with the performance index were slightly larger than that of the suspension travel.

On the other hand, the control input voltages of the two tuning methods were fairly similar (see Figure 7), whereas the control force of the DE-optimized case was considerably better in both peak and RMS values and had a transient behaviour (see Table 3 and Figure 11). In reality, the direct opposite would have been anticipated as a larger actuation force is often required to minimise the suspension travel, road holding, and vehicle handling which was previously reported. However, the inherent coupling as well as nonlinearities in this full-car system plays a significant role in altering such relationships. The fact that the DE-optimized case was able to produce such a solution infers that it is fully capable of dealing with nonlinearities and coupling.

However, the controlled cases did possess a drawback in terms of chattering, with the DE-optimized case being more severe. Such a response could be due to the marginally 


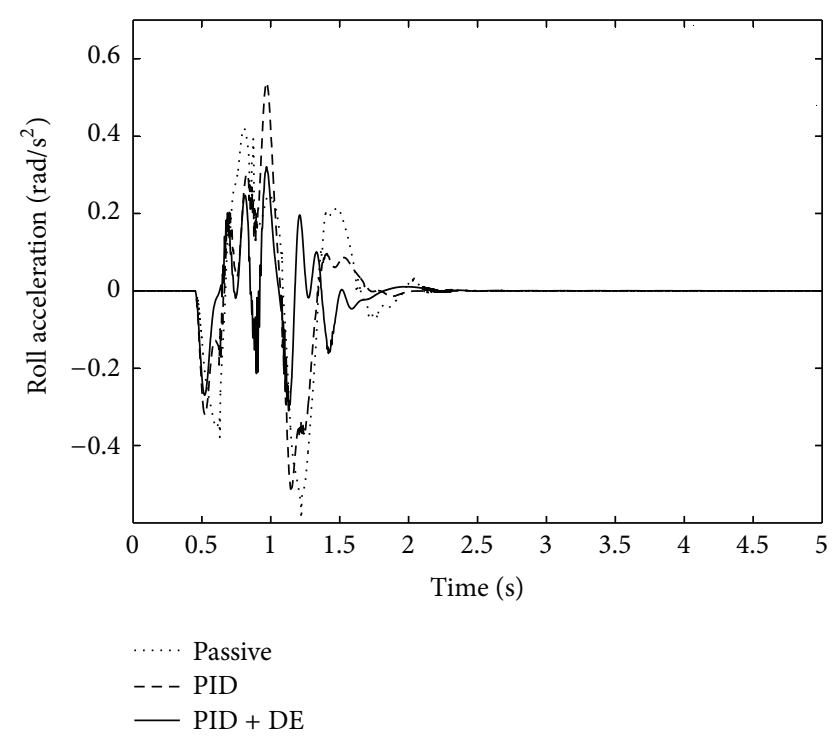

FIGURE 9: Time response of the roll acceleration for the passive and the proposed tuning methods.

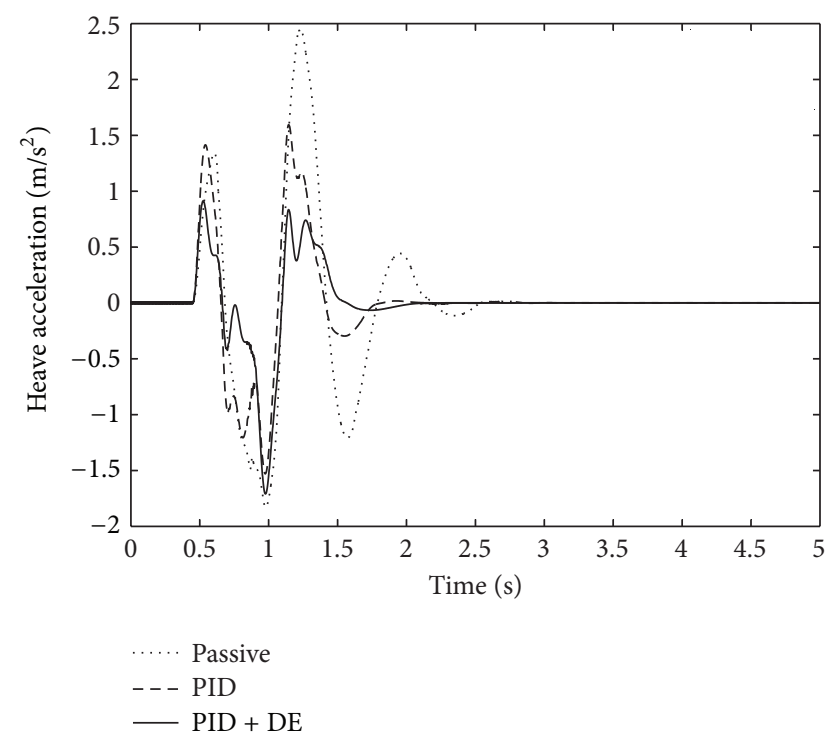

FIGURE 10: Time response of the body-heave acceleration for the passive and the proposed tuning methods.

high outer control loop gains used computed by the DE optimization algorithm. Such behaviour is undesirable as it will lead to component degradation.

5.1. Sensitivity to Parameter Variations Analysis. Each of the results plotted possessed a steady-state error that was in the order of magnitude of $0.001 \%$ of the peak values. Furthermore, a stability study was conducted to test the control systems sensitivity to parameter variations. The parameter variations apply to the mass and inertia of the vehicle, as the chassis will fluctuate in mass due to variations in fuel and passengers, tyre damping and stiffness, as the wheels will experience changes in pressure, and vehicle speed. Such

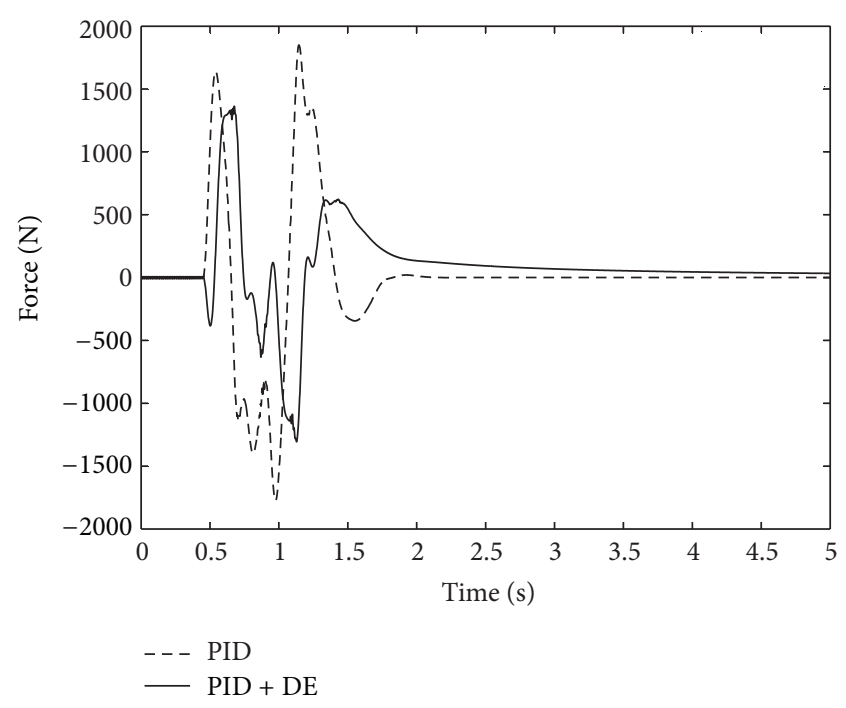

FIGURE 11: Time response of the electrohydraulic actuator force for the proposed tuning methods.

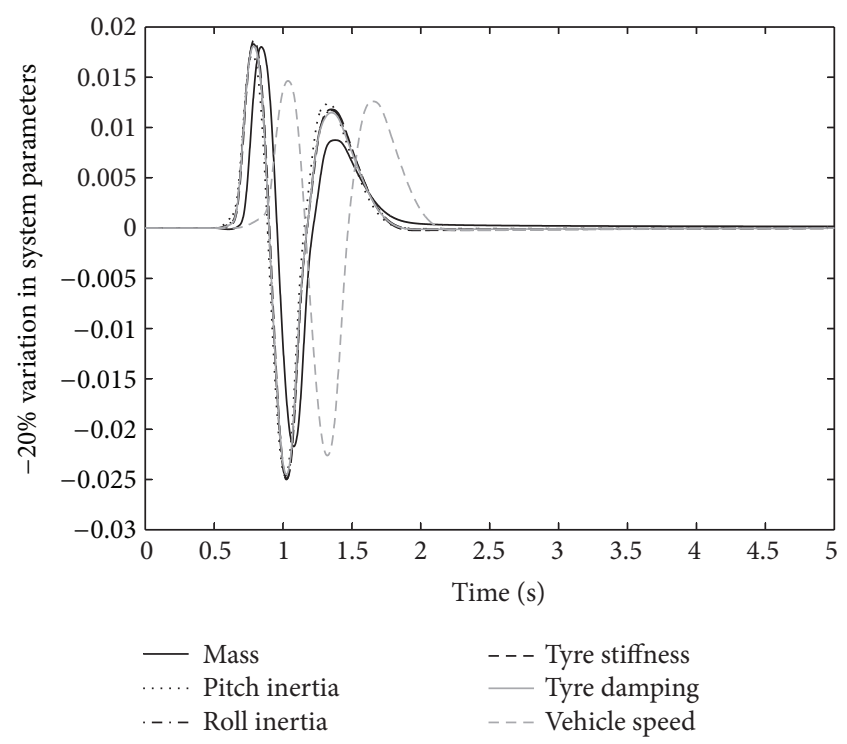

FIgURE 12: Suspension travel response of the DE-based PIDcontrolled case for a $-20 \%$ variation in selected parameters.

parameters are expected to change within a range of $\pm 20 \%$, and hence a sensitivity investigation was conducted along these lines. Since the DE-optimized case produced the most favourable results, stability is conducted on it. Figures 12 and 13 show the suspension travel response at the rear left wheel for $-20 \%$ and $+20 \%$ variations in the selected parameters, respectively.

Figures 12 and 13 show that the control system remains bounded-input-bounded-output (BIBO) stable within an acceptable steady-state error for all anticipated parameter variations. Apart from the $+20 \%$ variation in vehicle speed, 


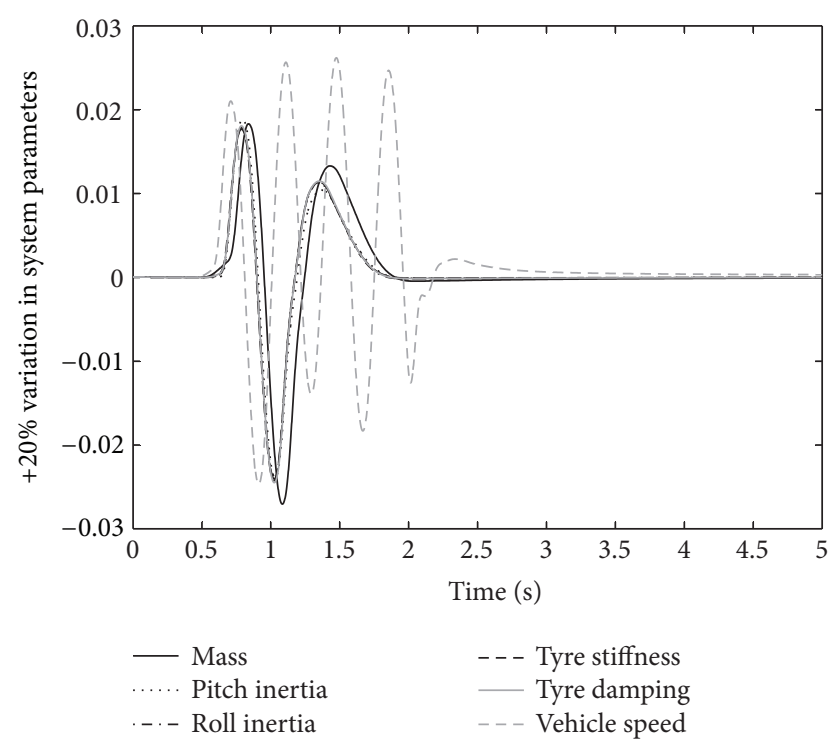

Figure 13: Suspension travel response of the DE-based PIDcontrolled case for $a+20 \%$ variation in selected parameters.

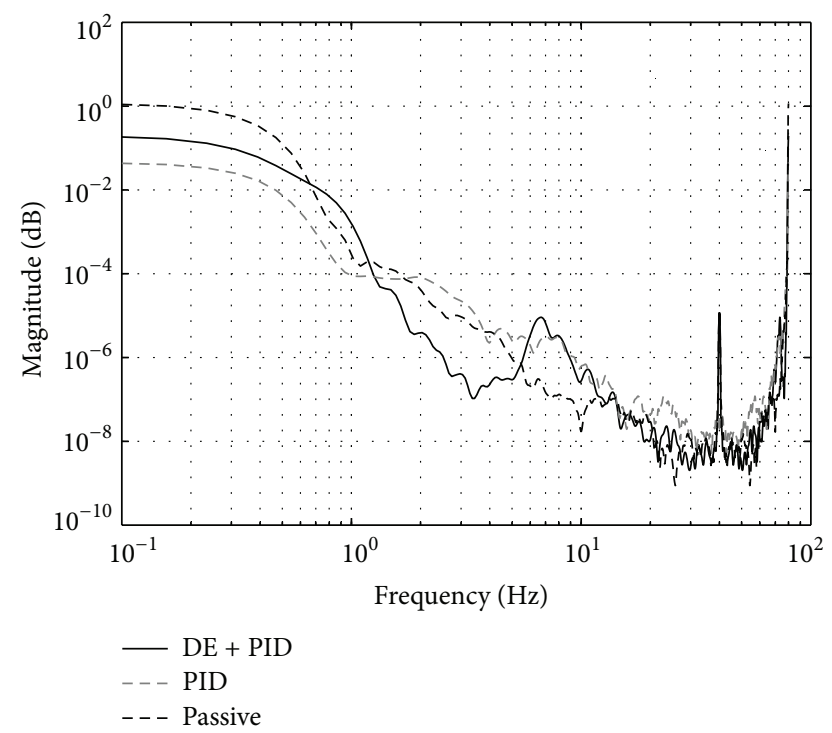

FIGURE 14: Frequency domain analysis of the body-heave acceleration.

the sensitivity was excellent with good transient behaviour and peak values. Hence, it may be concluded that the DE-based PID controller has an acceptable sensitivity to parameter variations except for a $20 \%$ increase in vehicle speed.

5.2. Frequency Domain Analysis. This section presents the pseudo-frequency domain analysis (based on power spectrum density estimation) for the vehicle ride comfort and handling characteristics. While vehicle ride comfort is commonly associated with the level of vibrations perceived by the occupants of the vehicle, it is also necessary to minimise the pitch and roll accelerations to obtain good handling. Analysis

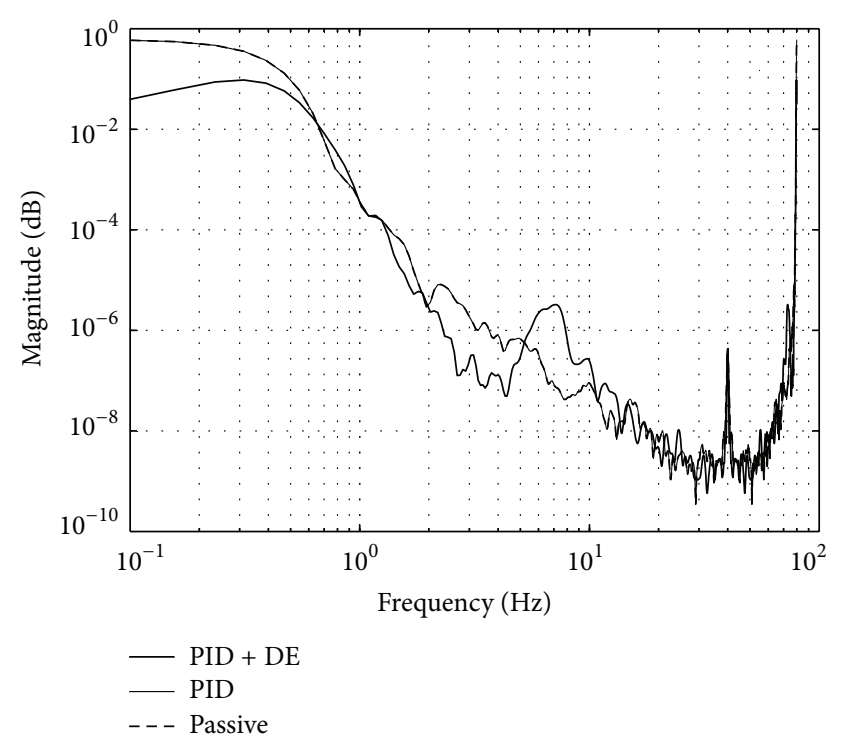

FIGURE 15: Frequency domain analysis of the pitch acceleration.

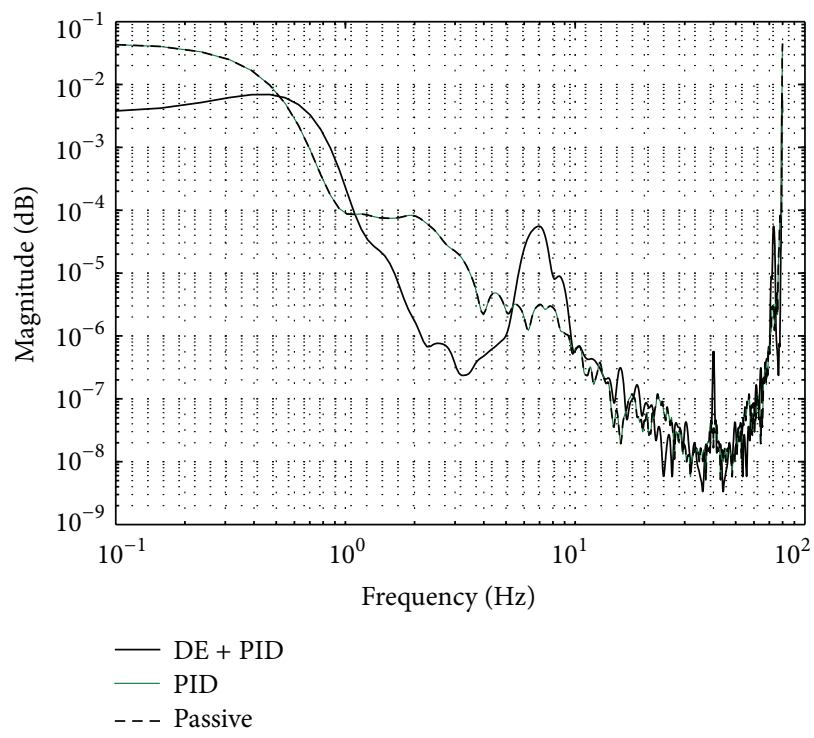

FIGURE 16: Frequency domain analysis of the roll acceleration.

for ride comfort is normally carried out in consonance with ISO $2631[36,38]$.

Figures 14-16 present a pseudo-frequency domain analysis carried out using the power-spectral-density-(PSD-) estimates based Welch algorithm in the MATLAB/Simulink signal processing toolbox. The Welch periodograms were computed using the following parameters: the windowing function-Hanning window function, the number of points used in forming each fast Fourier transform, NFFT $=1024$, and length of the window, NWind $=256$; and the sampling frequency of the windows was set at $80 \mathrm{~Hz}$ to accommodate the whole-body vibration (WBV) range.

Figure 14 presents the frequency weighted vehicle bodyheave acceleration mode. This mode of acceleration is most 
critical in the estimation of vehicle ride comfort. The analysis presented covers $0.5-80 \mathrm{~Hz}$, which is the WBV frequency range. This range includes the critical frequency ranges that need to be avoided for both human and vehicle comfort. Apart from the PID-controlled AVSS whose magnitude reached $1 \mathrm{~dB}$ at the onset of the analysis, all the signals showed attenuation until a sharp resonance occurred around $40 \mathrm{~Hz}$. The attenuation trend stopped around $80 \mathrm{~Hz}$.

Figures 15 and 16 show similar trend for the pitch and roll acceleration modes. The signals for the PID-controlled AVSS and the PVSS coincided all through the range of the analysis. All the signals showed attenuation of the signals at frequencies below $80 \mathrm{~Hz}$, except at $40 \mathrm{~Hz}$ where there was a sharp spike of resonance.

\section{Conclusion}

DE-optimized multi-loop PID-based control involving force feedback produced significant improvements in comparison to the PVSS and manually tuned cases. The recommended DE optimization was successful both in improving the performance index of the AVSS and in finding a better compromise between the conflicting AVSS design requirements. It also attained superior RMS and peak values in suspension travel, road holding, vehicle handling, and cumulative actuation force as compared to the manually tuned PID-controlled case. The observed reduction in actuation force is counterintuitive as larger forces are often required to minimise the other performance criteria. However, when dealing with nonlinear and coupled systems such as the full-car AVSS, this is possible, which infers that the DE-based optimization algorithm was able to account for coupling and nonlinearities as well. Chattering was the only shortfall of the controlled systems as it would degrade system components.

\section{References}

[1] J. D. J. Lozoya-Santos, R. Morales-Menendez, and R. A. RamrezMendoza, "Control of an automotive semi-active suspension," Mathematical Problems in Engineering, vol. 2012, Article ID 218106, 21 pages, 2012.

[2] J. E. D. Ekoru, O. A. Dahunsi, and J. O. Pedro, "PID control of a nonlinear half-car active suspension system via force feedback," in Proceedings of the IEEE AFRICON, Livingstone, Zambia, September 2011.

[3] Y. Sam and K. Huda, "Modelling and force tracking of hydraulic actuator for an active suspension system," in Proceedings of the IEEE International Conference on Industrial Electronics and Applications (ICIEA '06), pp. 1-6, Singapore, 2006.

[4] P. Gaspar, Z. Szabo, G. Szederkenyi, and J. Bokor, "Design of a two-level controller for an active suspension system," Asian Journal of Control, vol. 14, no. 3, pp. 664-678, 2012.

[5] D. Hrovat, "Survey of advanced suspension developments and related optimal control applications," Automatica, vol. 33, no. 10, pp. 1781-1817, 1997.

[6] L. Chai and T. Sun, "The design of LQG controller for active suspension based on analytic hierarchy process," Mathematical Problems in Engineering, vol. 2010, Article ID 701951, 19 pages, 2010.
[7] J. O. Pedro, " $\mathrm{H}_{2}$-LQG/LTR controller design for active suspension systems. R and D," Journal of the South African inStitution of Mechanical Engineering, vol. 23, no. 2, pp. 32-41, 2007.

[8] J. Marzbanrad, G. Ahmardi, Y. Hojjat, and H. Zohoor, “Optimal active control of vehicle suspension system including time delay and preview for rough roads," Journal of Vibration and Control, vol. 8, no. 7, pp. 967-991, 2002.

[9] J. Cao, H. Liu, P. Li, and D. Brown, "State of the art in vehicle active suspension adaptive control systems based on intelligent methodologies," IEEE Transactions of Intelligent Transportation Systems, vol. 9, no. 3, pp. 392-405, 2008.

[10] C. Kaddissi, M. Saad, and J.-P. Kenné, "Interlaced backstepping and integrator forwarding for nonlinear control of an electrohydraulic active suspension," Journal of Vibration and Control, vol. 15, no. 1, pp. 101-131, 2009.

[11] C.-J. Huang, T.-H. S. Li, and C.-C. Chen, "Fuzzy feedback linearization control for MIMO nonlinear system and its application to full-vehicle suspension system," Circuits, Systems, and Signal Processing, vol. 28, no. 6, pp. 959-991, 2009.

[12] O. Kaynak, K. Erbatur, and M. Ertugrul, "The fusion of computationally intelligent methodologies and sliding-mode control-a survey," IEEE Transactions on Industrial Electronics, vol. 48, no. 1, pp. 4-17, 2001.

[13] O. A. Dahunsi, J. O. Pedro, and O. T. Nyandoro, "System identification and neural network based PID control of servohydraulic vehicle suspension systems. Transactions of the South African Institute of Electrical Engineersion (SAIEE)," Africa Research Journal, vol. 101, no. 3, pp. 93-105, 2010.

[14] J. O. Pedro, O. A. Dahunsi, and N. Baloyi, "Direct adaptive neural control of a quarter-car active suspension susytem," in Proceedings of the IEEE AFRICON, Livingstone, Zambia, 2011.

[15] J. Zhang and J. Chen, "Neural PID control strategy for networked process control," Mathematical Problems in Engineering, vol. 2013, Article ID 752489, 11 pages, 2013.

[16] K. H. Ang, G. Chong, and Y. Li, "PID control system analysis, design, and technology," IEEE Transactions on Control Systems Technology, vol. 13, no. 4, pp. 559-576, 2005.

[17] I. Chiha, J. Ghabi, and N. Liouane, "Tuning PID controller with multi-objective differential evolution," in Proceedings of the 5th international Symposium on Communications, Control and Signal Processing (ISCCSP '12), Rome, Italy, 2012.

[18] M. W. Iruthayarajan and S. Baskar, "Evolutionary algorithms based design of multivariable PID controller," Expert Systems with Applications, vol. 36, no. 5, pp. 9159-9167, 2009.

[19] B. Nagaraj and P. Vijayakumar, "A comparative study of PID controller tuning using GA, PSO, EP and ACO," Journal of Automation, Mobile Robotics and Intelligent Systems, vol. 5, no. 2, pp. 42-48, 2011.

[20] R.-J. Wai, J.-D. Lee, and K.-L. Chuang, "Real-time PID control strategy for maglev transportation system via particle swarm optimization," IEEE Transactions on Industrial Electronics, vol. 58, no. 2, pp. 629-646, 2011.

[21] H. Du, J. Lam, and K. Y. Sze, "Non-fragile output feedback Ho vehicle suspension control using genetic algorithm," Engineering Applications of Artificial Intelligence, vol. 16, no. 7-8, pp. 667680, 2003.

[22] Y. He and J. McPhee, "A design methodology for mechatronic vehicles: application of multidisciplinary optimization, multibody dynamics and genetic algorithms," Vehicle System Dynamics, vol. 43, no. 10, pp. 697-733, 2005. 
[23] J.-S. Chiou, S.-H. Tsai, and M. -T. Liu, "A PSO-based adaptive fuzzy PID-controllers," Simulation Modelling Practice and Theory, vol. 26, no. 8, pp. 49-59, 2012.

[24] R. Kothandaraman and L. Ponnusamy, "PSO tuned adaptive neuro-fuzzy controller for vehicle suspension systems," Journal of Advances in Information Technology, vol. 3, no. 1, pp. 57-63, 2012.

[25] T. Kloiber, G. Koch, and B. Lohmann, "Modified optimal control of a nonlinear active suspension system," in Proceedings of the 49th IEEE Conference on Decision and Control (CDC '10), pp. 5572-5577, Atlanta, Ga, USA, December 2010.

[26] M. M. Ali, "Differential evolution with generalized differentials," Journal of Computational and Applied Mathematics, vol. 235, no. 8, pp. 2205-2216, 2011.

[27] W.-H. Ho and A. L.-F. Chan, "Hybrid Taguchi-differential evolution algorithm for parameter estimation of differential equation models with application to HIV dynamics," Mathematical Problems in Engineering, vol. 2011, Article ID 514756, 14 pages, 2011.

[28] A. Ketabi and M. J. Navardi, "Optimization shape of variable capacitance micromotor using differential evolution algorithm," Mathematical Problems in Engineering, vol. 2010, Article ID 909240, 15 pages, 2010.

[29] M. S. Saad, H. Jamaluddin, and I. Z. N. Darus, "Implementation of PID controller tuning using differential evolution and genetic algorithms," International Journal of Innovative Computing, Information and Control, vol. 8, no. 11, pp. 7761-7779, 2012.

[30] Y. Luo and X. Che, "Tuning PID control parameters on hydraulic servo control system based on differential evolution algorithm," in Proceedings of the 2nd International Conference on Advanced Computer Control (ICACC '10), pp. 348-351, Shenyang, China, March 2010.

[31] M. M. Ali, "A derivative-free variant called DFSA of Dekkers and Aarts continuous simulated annealing algorithm," Applied Mathematics and Computation, vol. 219, no. 1, pp. 604-616, 2012.

[32] J. Yan, B. Li, H.-F. Ling, H.-S. Chen, and M.-J. Zhang, "Nonlinear state space modeling and system identification for electrohydraulic control," Mathematical Problems in Engineering, vol. 2013, Article ID 973903, 9 pages, 2013.

[33] I. J. Fialho and G. J. Balas, "Design of nonlinear controllers for active vehicle suspensions using parameter-varying control synthesis," Vehicle System Dynamics, vol. 33, no. 5, pp. 351-370, 2000.

[34] B. L. J. Gysen, J. J. H. Paulides, J. L. G. Janssen, and E. A. Lomonova, "Active electromagnetic suspension system for improved vehicle dynamics," IEEE Transactions on Vehicular Technology, vol. 59, no. 3, pp. 1156-1163, 2010.

[35] D. Fischer and R. Isermann, "Mechatronic semi-active and active vehicle suspensions," Control Engineering Practice, vol. 12, no. 11, pp. 1353-1367, 2004.

[36] M. J. Griffin, "Discomfort from feeling vehicle vibration," Vehicle System Dynamics, vol. 45, no. 7-8, pp. 679-698, 2007.

[37] European Commission, "Directive 2002/44/EC of the European Parliament and the Council of 25 June 2002 on the minimum health and safety requirements regarding the exposure of workers to the risk arising from physical agents (vibration)," Official Journal of the European Communities, Luxembourg, 2002.

[38] ISO 2631, Mechanical Vibration and Shock-Evaluation of Human Exposure to Whole-Body Vibration-Part 1: General Requirements, International Organization for Standardization, Geneva, Switzerland, 2003. 


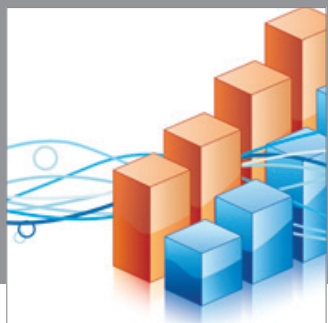

Advances in

Operations Research

mansans

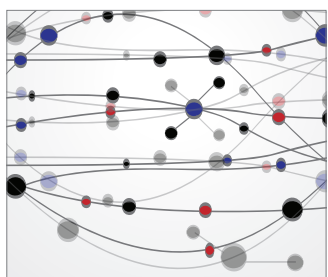

The Scientific World Journal
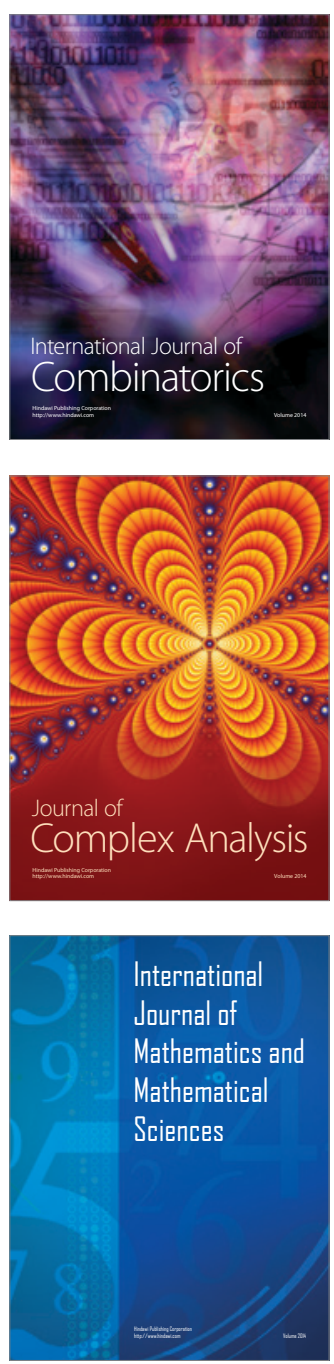
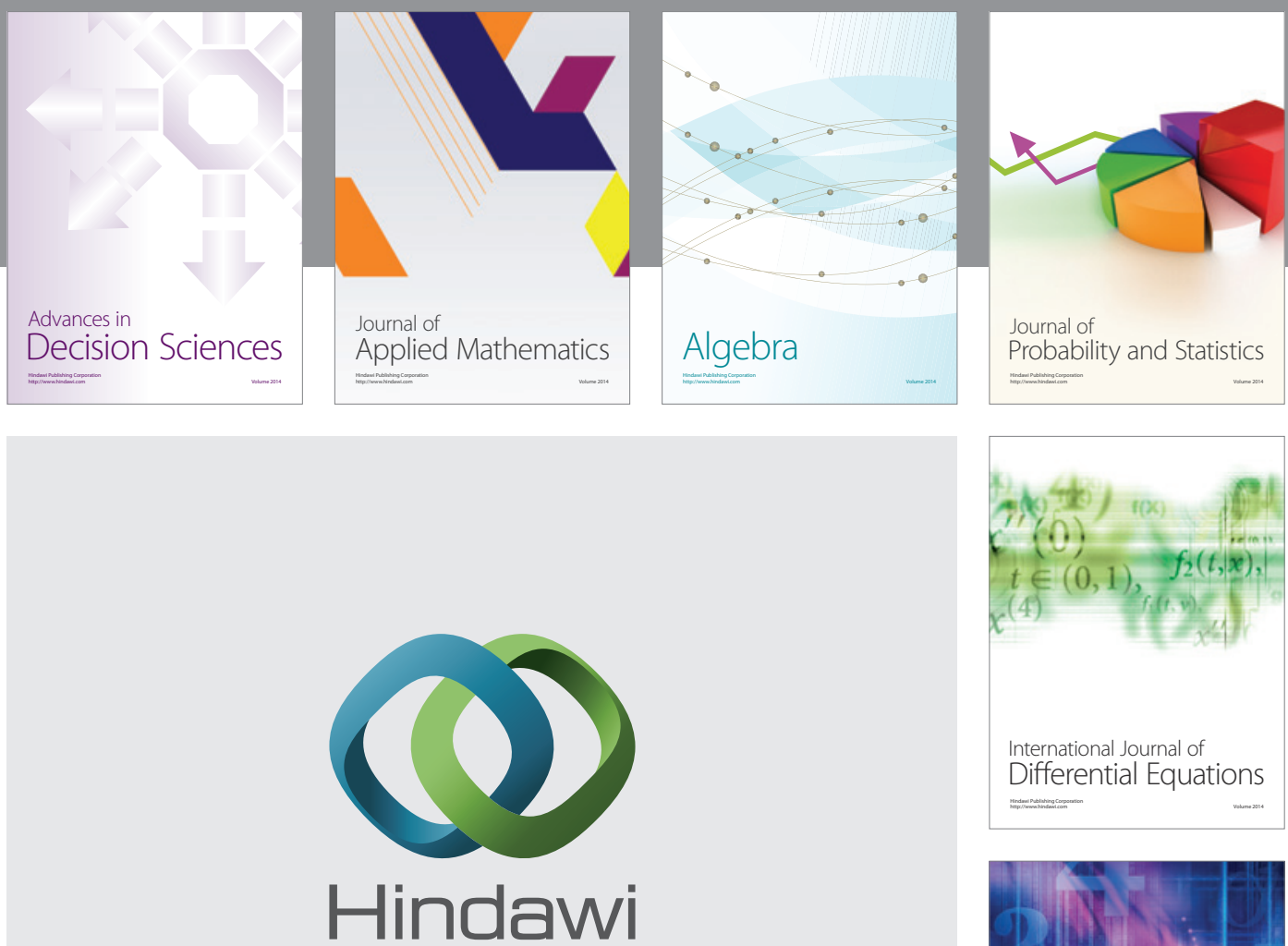

Submit your manuscripts at http://www.hindawi.com
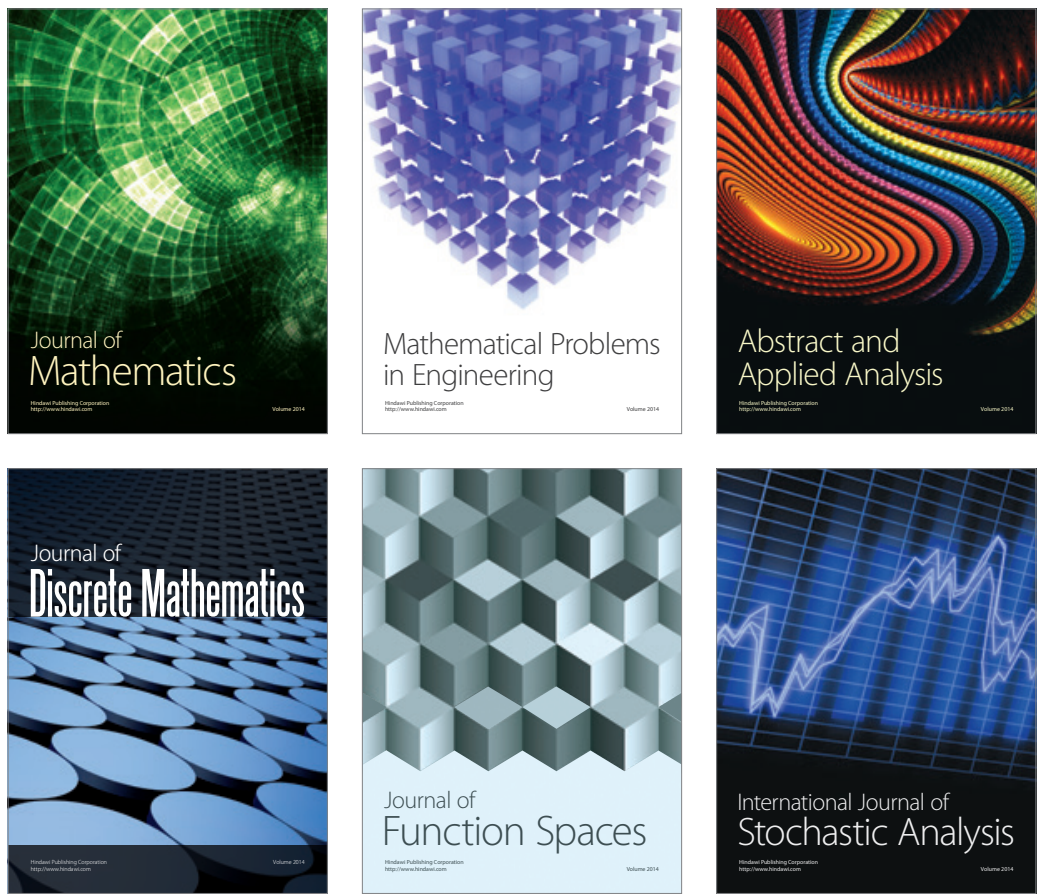

Journal of

Function Spaces

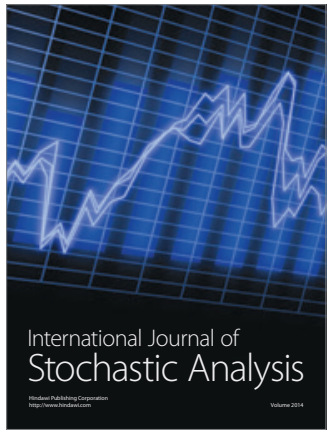

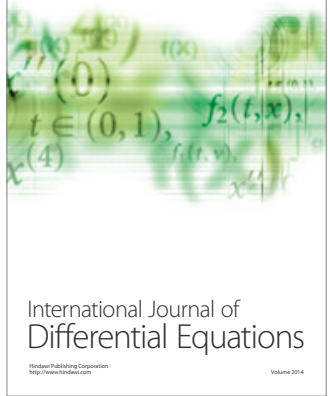
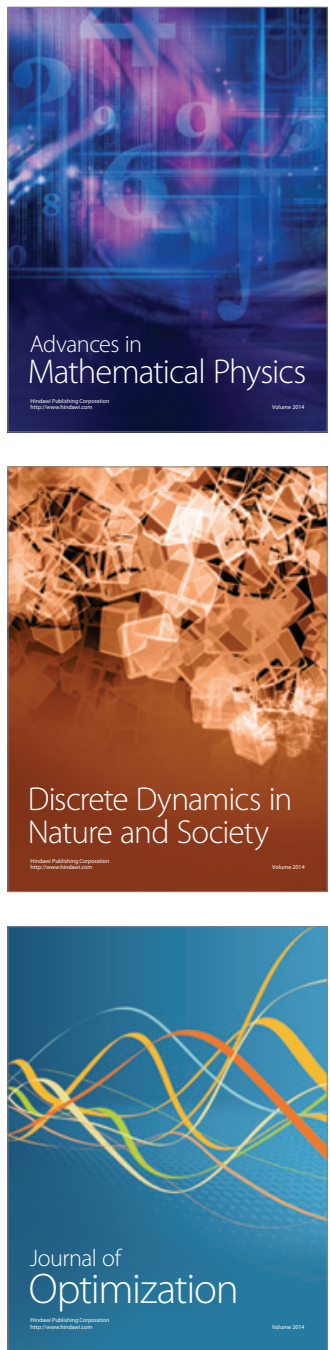